\section{Family involvement in the care of people with}

\section{psychoses}

\author{
An ethical argument
}

\section{GEORGE I. SZMUKLER and SIDNEY BLOCH}

Growing evidence points to the benefits of involving relatives (or other informal carers) in treating people suffering from a psychosis. Psychoeducational approaches, for instance, are associated with a reduced relapse rate in schizophrenia and offer potential for better family coping and a diminution in their distress (Falloon \& Pederson, 1985; Lam, 1991; Bloch et al, 1994). Furthermore, the family commonly provides useful information about the patient and their illness; this facilitates a treatment plan in which the family can play a prominent role in helping to supervise medication, encouraging participation in rehabilitation programmes, and generally providing an environment conducive to promoting recovery or reducing disability. However, achieving optimal collaboration with the family is often beset with difficulties of an ethical nature, especially revolving around confidentiality, and its potential breach. A specially taxing problem concerns the circumstances when the involvement of the family is justified despite a patient's refusal to provide consent.

We focus on patients with psychotic disorders because the benefits of family involvement are established and because the validity of their refusal is sometimes unclear in that their illness may affect their capacity to judge what is in their best interests. Furthermore, the crucial role of carers in making 'community care' possible is increasingly recognised, carrying with it a right to respect their needs.

The purposes of this paper are twofold. The first is to outline an approach to family collaboration sensitive to the issues of confidentiality and the potentially competing interests of patient and family. We hope that such an approach will establish from the outset a treatment relationship with both patient and family in which later ethical dilemmas are mostly avoided. The second is to offer guidelines where a patient refuses family involvement even though the interests of one or both are likely to be served. We hope our suggestions will provoke discussion of a neglected area, and so lead to agreed principles of good practice.

Before proceeding further we enter a major caveat concerning cultural differences in value systems, both inside and outside the family. Our discussion is geared to psychiatry in Western countries, but even here value differences between ethnic groups, or even generations within families, may create difficulties. A consultation with a patient in an Indian family may encounter different expectations of family involvement - for example, who should be present, who is entitled to know what, and who should make decisions - to an English one. Such differences cannot be addressed in this paper, but we ask the reader to bear in mind their possible influences.

\section{CONFIDENTIALITY}

Confidentiality, a core ethical principle in medicine as part of respect for a person's privacy, is supported by other values which enhance the doctor-patient relationship (Beauchamp \& Childress, 1988). These include respect for autonomy and a community interest in encouraging patients to feel secure in being open with their doctors, thus facilitating accurate diagnosis and treatment. However, confidentiality cannot be absolute and may be justifiably breached as a result of competing interests. For example, in many jurisdictions notifying authorities of specified diseases is mandatory, and information about patients may be revealed where failure to do so could expose them or others to risk of serious harm. Here patient consent is not essential, although it should be sought whenever possible as part of good practice.

Frequently in the course of a psychosis, confidentiality is necessarily breached in the patient's interests or to protect others. A clear example is in the instigation of compulsory treatment under mental health law where others (relatives, other doctors, social workers, police, ambulance officers) become involved even if this is contrary to the patient's wishes. Other situations commonly arise, short of those warranting compulsory treatment, in which the interests of patient or others, especially family, appear to necessitate disclosure of confidential information. But uncertainty prevails about when such action is justified. Psychiatrists' concerns may hinder both effective treatment of the seriously ill and the addressing of their carers' needs.

Before offering our ideas on dealing with these challenging circumstances, we provide an ethical framework for engaging families in treatment, which seeks to clarify key aspects of their participation.

\section{AN ETHICALLY SENSITIVE APPROACH TO FAMILY INVOLVEMENT}

An ethical framework for all psychiatric interventions with the family entails the role of values, the question of how to balance the interests of its members, informed consent, and confidentiality.

\section{Values and family intervention}

Whatever the form of family engagement, the psychiatrist enters a moral arena. The concept of a morally neutral clinical encounter is fanciful despite the determination to maintain an objective ethical stance. A value system is crucial to a family's welfare; if undetermined its stability could well be jeopardised. These risks are magnified in the clinical context since values held by family members may be linked to the patient's difficulties or to related systemic problems. Helpful guidelines have been elaborated by Aponte (1985) and Bloch et al (1994) for dealing with this issue:

(a) The family's role in trying to understand its difficulties and seeking to work out solutions is respected, and kept to the forefront throughout treatment.

(b) The clinician offers professional knowledge and skills as required, but not at the expense of depriving the family of the opportunity to use their own strengths.

(c) The clinician takes care to withhold his or her values, especially avoiding the imposition of what he or she regards as 'right' for the family. 
(d) The clinician does, however, convey when appropriate the desirability for the family to explore their values so that related changes in functioning can be considered.

(e) The clinician is active in highlighting any conflicting values in the family in the expectation that differences can be explored and dealt with.

\section{The relative interests of family members}

How does the psychiatrist respond to the interests of family members, especially if they clash with one another? Three basic positions have been proposed:

(a) The patient's interests always take priority, with the rest of the family regarded as ancillary. Although their potential contribution is sought, this is construed as assistance to the patient.

(b) While the interests of family members are taken into account, the particular features of the therapeutic situation guide the clinician's responses. Thus, he or she may attend to the patient at one point but switch to other members, for example, the patient's principal carer at another time. The patient is not always the chief priority; indeed, satisfactory functioning may sometimes be at the expense of others. Moreover, given that family members' well-being may change during treatment, the clinician monitors the welfare of each and adjusts interventions accordingly.

(c) The interests of all family members are relevant without exception, on the premise that their dynamics as a social group and the patient's difficulties are inextricably linked. The psychiatrist is correspondingly obliged to consider carefully and take into account as far as possible the interests of each.

The third position is least applicable to the psychoses since systemic explanations of their origins are weak. One could argue pragmatically that any of the three positions could prevail according to specific clinical circumstances. We think otherwise and suggest that the second option best suits the majority of interventions with the family. By adopting a broad-based approach, we commit ourselves to a stance which gives due place to the contribution of the family in understanding the causes, outcome and treatment of mental illness. We convey that all may need to participate if the treatment is to be well implemented. It follows that clinicians have a responsibility to ensure that all family members' interests are respected. Thus, whatever their status (especially as patient or otherwise) or values, all are given appropriate attention. Given the nature of psychosis, it is likely that the patient will require more of the psychiatrist's expertise, but still not at the expense of the rest of the family.

A key point here is that this potentially disproportionate therapeutic allocation must be clarified with patient and family when the latter are recruited. The procedure of informed consent served well to engage the family according to our preferred position. We turn to this subject now to note its central role in working with the family.

\section{Informed consent}

Informed consent is the foundation upon which ethically sound care of patients and their families occurs. A common sequence in the case of the psychotic patient entails psychiatric assessment followed by interviews with one or more family members, then possible meetings as a group. The ingredients of the consent process are that the psychiatrist: (a) explains the purposes, benefits and risks of the family's involvement; (b) ensures that all participants including the patient comprehend this in formation; (c) ensures that the family consents freely - without coercion - although they may harbour concerns; and (d) stipulates that although consent is being sought at this juncture, it is subject to re-negotiation if family members should wish it.

Informed consent is thus a dynamic process - a continuing dialogue between psychiatrist and family. Psychiatrist, patient and family unite in determining what is therapeutically advantageous. The clinician accepts that some members may refuse to participate. In the event, he or she adheres to the principle of respect for autonomy in recognising the family's varied preferences. Neither family members declining nor remaining are discriminated against by, for instance, veiled threats that further help will not be offered unless all cooperate.

\section{Confidentiality in working with the family}

Preserving confidences where the family is involved is unquestionably problematic (Fieldsteel, 1982; Lakin, 1988; Doherty \& Boss, 1991; Goldenberg \& Goldenberg, 1991). The process may entail sharing sensitive information about not only the patient but also the family. The patient or a family member may request, even insist, that specified material should not be divulged to the others. Yet the information may be necessary for the optimal conduct of treatment (examples are a history of sexual or physical abuse, domestic violence or an extra-marital affair). The psychiatrist then faces a dilemma. The material may be central to the family's welfare, or to an understanding of the patient's problems. But insistence on breaching confidentiality may well jeopardise the alliance with patient or family. Similar difficulties may arise when clinically relevant secrets are shared by some family members, excluding others.

Solutions for these dilemmas are elusive; they both test and legitimise 'professionalism'. However, three options can be proposed (Margolin, 1982):

(a) Confidences are sacrosanct and family members are not pressed to divulge them.

(b) The psychiatrist discourages family members from confiding in him alone. He contracts with the family not to be shackled by secrets, perhaps by not meeting with any member separately, thus pre-empting any collusion.

(c) The psychiatrist is flexible inasmuch as information is generally shared among family members but on the understanding they have the right to keep intensely personal information private.

Arguments can be advanced for each but the degree of difference between them points to the question resisting a straightforward remedy. However, one issue is none the less clear: the clinician is obliged to share his or her preferred option with the family, together with its rationale, advantages and risks (although flexibility is retained with the possibility of re-negotiation later if circumstances change).

\section{SITUATIONS WHERE PATIENTS REFUSE FAMILY INVOLVEMENT}

We anticipate that the approach we have outlined will reduce dilemmas concerning family involvement in the treatment of psychotic patients. However, complicated instances remain when the psychiatrist will consider contacting relatives despite the patient's refusal to give consent. We start with the premise that confidentiality is presumed. When it is breached, the onus falls on the psychiatrist for justification. We 
divide our discussion as follows: we first consider further attempts to obtain the patient's consent; we then discuss the grounds for acting without consent, firstly in the patient's interests, and secondly in the family's interests.

\section{An initial response}

The clinician can persevere in seeking the patient's consent. Two aspects are relevant. The first is a detailed explanation of the reasons for seeking family involvement. If our advice, above, concerning family recruitment is accepted, it is emphasised that this is routine. The benefits can be highlighted - the patient's problems can be better understood, the family can provide support, the clinician needs the family's help with treatment, the outcome will probably be enhanced, and family members may well have their own need to understand the nature of the illness and the treatment proposed. The second aspect is an attempt to understand the reasons behind the patient's refusal. Does it arise out of set patterns of family communication, or the family's value system, or previous unhappy incidents? Exploring the patient's predictions about how family members might react to receiving certain information about his or her condition may yield fears in a nonconfronting way. Family involvement might also significantly alter the patient's relationship with the clinician as well as others, like peers or a partner. An undertaking to address the patient's anxieties can be made explicit in these circumstances. Furthermore, the psychiatrist weighs up the advantages of asking the patient to be present when the relatives are seen.

If approval for family contact is still unobtainable, the psychiatrist can negotiate restricted conditions. For example, only agreed questions will be posed or agreed items of information disclosed (e.g. medication and side-effects, self-help organisations for carers). If this strategy fails, the patient might agree to contact by correspondence, including reading the letter.

\section{When might a patient's refusal be overridden?}

If this initial response fails, the complex matter of overriding the patient's refusal comes into play. Grounds for such drastic action are either clearly established or more ambiguous. The former correspond in general with the grounds for considering compulsory admission to hospital. Central to these is a serious risk to the patient's safety or health or to the safety of others. For example, under section 3 of the Mental Health Act 1983 for England and Wales, the approved social worker is obliged to discuss the patient's plight with the nearest relative and to obtain his or her agreement.

Our discussion will now focus on less clearly established grounds. These involve risks, short of dangers to physical safety, (a) to the health or well-being of the patient or (b) to the well-being of the family. Different 'ends' apply to these two sets of circumstances, requiring consideration of separate principles.

\section{Risks to the patient's health or well-being}

The risk falls short of that warranting compulsory admission. The patient is often in the process of relapse with a likelihood that compulsion will become necessary later. Preventing further deterioration may be an immediate goal. Common risks include severe self-neglect, loss of accommodation, job, money or friends, intense distress, exploitation by others, predictable worsening of symptoms, or deterioration to a point which jeopardises future rehabilitation. The psychiatrist may judge that the patient's family may be able to help by, for example, providing information, offering support, supervising medication or ensuring a safe environment.

The dilemma concerning confidentiality posed by a patient who refuses contact with the family turns on the balance between the competing values of respect for autonomy versus paternalism. A further consideration is the future doctor-patient relationship if confidentiality is breached. Many psychiatrists hold that without grounds for compulsory admission, respect for autonomy is paramount. This may be a considered position, but may well arise out of a fear of departing from a hallowed principle.

If respect for autonomy is not an absolute determinant, what factors should be weighed in the balance in deciding to act against the patient's wishes? We propose the following:

(a) The nature and magnitude of the harms to be avoided, and the probability of their occurrence.

(b) The availability of alternatives which might reduce the likelihood of harm. Other people or helping agencies which the patient may be happy to deal with may be able to alleviate the harms. (c) The patient's capacity to make choices. In assessing the patient's capacity to make decisions about treatment, we consider the ability to comprehend the nature and purpose of the proposed treatment, the likely outcome if treatment is not given, and possible adverse effects. Furthermore, the patient should be able to make a 'true choice', that is, one unaffected by distorted ideas such as delusions. If such a test were to be applied, would the patient be deemed to have capacity to decide on the value of family involvement?

(d) The values of patient and family might suggest how family contact will be received. A family typified by good relationships and mutual support, but which the patient, as a result of the psychosis, sees as rejecting, might be regarded differently to a long-standing dysfunctional one. Cultural norms concerning the role of the family of an ill person in general may also be relevant. Following recovery, would the patient be likely to see family involvement as having been desirable? Has previous discussion with patient or family revealed that contact would be acceptable, given the current circumstances?

(e) The principle of 'the least restrictive' option could apply when family involvement will reduce the likelihood of a greater restriction on the patient's freedom, especially involuntary hospitalisation. This principle is explicit in some mental health statutes, for example in Victoria, Australia, but not in others. But even in the latter case, it is implicit in certain circumstances, as in the requirement to consult the nearest relative before compelling admission under section 3 of the Mental Health Act 1983 for England and Wales.

In summary, justification for involving the family contrary to the patient's wishes would be strongest when: the harms to be avoided are serious and highly probable; no acceptable alternatives are available; the patient's capacity to make a genuine choice is impaired; the family's values embody mutual concern and assistance; and not recruiting the family may lead to even greater restrictions on the patient's liberty. Also to be kept in mind is the potential effect on the future doctor-patient relationship were confidentiality to be breached, and whether harms avoided in the short term will be outweighed by those in the long term arising from a breakdown in the therapeutic 
alliance. The clinical context may be important here. The psychiatrist may act differently depending on how long he or she has known the patient and the quality of their relationship.

\section{Risks to the well-being of the family}

At present it is unlikely that many psychiatrists would involve the family without the patient's consent out of concern about their well-being (short of serious, physical danger). Yet we are all familiar with families who experience bafflement, anguish, burdensome behaviours, and even intimidation as a result of their relative's illness. Some may approach the clinician for help; others may wish to do so but feel too frightened. It comes as a harsh blow if they are told that information cannot be given because of 'patient confidentiality'.

Does the psychiatrist have a duty of care towards such carers, over and above that to the patient? The question has been largely ignored and we recognise we are moving into largely uncharted waters. However, with increased family participation in treatment, ambiguities abound which do need sorting out. Consider the following developments.

The 1995 Mental Health (Patients in the Community) Act for England and Wales introduced 'supervised discharge' for certain categories of patient who pose risks of serious harm to themselves or others in the absence of after-care services. It is noteworthy that an informal carer must be consulted when making an application, as well as later if changes to the care plan prove necessary, including stopping the order. The patient cannot object to this consultation, but can object to the 'nearest relative' being informed if this person is not the 'carer'.

Guidance from the Department of Health (1996) in England and Wales - The Protection and Use of Patient Information-shows inconsistency concerning carers. In one section (2.6) which deals with information being divulged to others without the patient's consent, a recipient who "needs the information because he or she is or may be concerned with the patient's care and treatment" has this right on a "need to know basis". A footnote states that "carers are often regarded as members of the care team" and are thus presumably covered. However, we read elsewhere (section 5.1): "With the patient's consent, the significant role of carers may need to be recognised in the type of information provided: for example, on discharge from hospital and to make arrangements for continuing care".

The Australian Medical Association's (1996) revised Code of Ethics states: "Keep in confidence information derived from your patient, and divulge it only with the patient's permission. Exceptions may arise where the health of others is at risk or you are required by order of a court to breach patient confidentiality" (emphasis added).

An explicit provision for carers to be informed is contained in recent changes to the Victoria (Australia) Mental Health Act, in which Section 120A (3) allows:

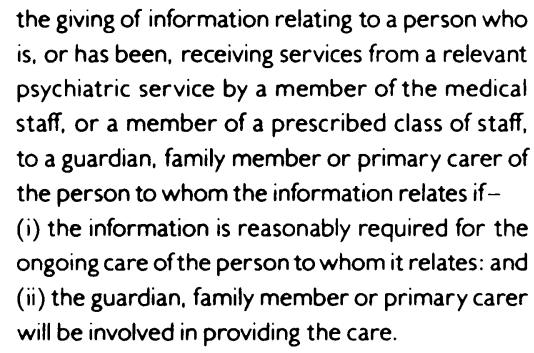

Thus, a trend towards the recognition of carers' interests has emerged recently, and this is likely to grow in parallel with the expanding role of informal carers as members of the care team in the community.

Several arguments can be marshalled for involving relatives, primarily for their own benefit, but against the patient's wishes. The first is to view the family as the unit of treatment. The best care of the patient requires the family's support. Moreover, the impact on the family of a member with a severe mental illness is so major that the psychiatrist has a duty of care to them. This case is strengthened by the philosophy of community care, which aims to preserve the patient's social links and to avoid institutional treatment. Further, it could be argued that often the treatment team alone has the requisite knowledge about the patient's illness to be able to help the family effectively. A more limited assistance might be obtainable by relatives seeking help elsewhere, for example from a self-help organisation or the general practitioner (GP). Presumably the GP would be just as constrained by the patient's objections as the psychiatrist. Indeed, if the GP serves both patient and family, a conflict of loyalty may prove even more troublesome. In any event, the 'unit of treatment' argument probably represents too radical a departure from traditional practice to gain widespread acceptance at present; for example, current General Medical Council (1995) guidance on confidentiality in the UK is unlikely to sanction it.

A further, more robust argument invokes the principle of justice or fairness. This has usually been applied to resolve competing claims for allocation of resources, but is also relevant in judging entitlements to other 'goods'. Such adjudication entails the identification of 'material principles' on which allocation should be determined, for example, 'needs' or 'equity'. In our context, should the needs of the family merit distinctive attention? If these can be met by someone outside the treatment team (for example, a self-help organisation) then the clinician's quandary is possibly alleviated. Alternatively, if resources capable of meeting the family's needs reside in major part within the treatment team, a set of duties to the family would seem to follow.

Probably the most compelling argument is to re-frame relatives' relationships to the patient as not only familial but also as 'carer'. As such they enjoy rights intrinsically attached to all carers, whether relatives or not. These cover at least an account of the illness and guidance about how to deal with the ill person's problems insofar as they impinge on the carer's life (Bloch et al, 1995). This might include details about other agencies that offer assistance. Provision of information is best governed by the 'need to know' principle. This would bring the family's position into alignment, for example, with that of a hostel support worker. A counter-argument might be that the patient has agreed to reside in a hostel and accepted that the terms include disclosure of relevant information. An ill relative may not 'choose' to live with the family in the same way. Against this, it could be asserted that obligations exist between family members so that if one is expected to care for another, he or she also has a claim to a necessary minimum of professional assistance. This type of thinking is consistent with the trend in legislation illustrated earlier which views 'carers' as having special status vis-à-vis the patient.

In summary, we contend that justifications can be advanced for providing family carers with material information aimed at meeting their interests. Several factors should be weighed up in judging when this is appropriate, some resembling those considered earlier: the seriousness of risk to the family's well-being, available alternatives, the patient's capacity to recognise actual and 
potential harms, and pre-existing family values. If information is to be disclosed non-consensually, it should be confined to a 'need to know' level, that is the minimum necessary for the carer to cope with the situation.

\section{CONCLUSIONS}

Radical changes in clinical practice require us to think differently about the interests of patients' families. In the era of community care we expect much from them, but this has not been balanced by mapping out our duties towards them. The time has arrived for mental health professionals to develop ethically sound practice guidelines facilitating family intervention. To this end we have offered our ideas on ways of engaging families which take account of confidentiality and competing interests. We have also considered grounds for involving families despite a patient's refusal. A central difficulty is that medical ethics in a traditional Western sense is concerned with the individual. Hence the struggle in attempting to marry it to a family-orientated model of clinical practice. We hope our contribution will stimulate debate and pave the way for a consensus

GEORGE I. SZMUKLER, FRANZCP. Bethlem and Maudsley NHS Trust, Maudsley Hospital; SIDNEY BLOCH. FRANZCP. University of Melbourne. St Vincent's Hospital, Victoria 3065, Australia

Correspondence: G. I. Szmukler, Bethlem and Maudsley NHS Trust, Maudsley Hospital, London SE5 8AZ

(First received 31 January 1997, final revision 21 May 1997, accepted 29 May 1997)

about what is ethically sound as well as clinically beneficial.

\section{ACKNOWLEDGEMENTS}

We thank Edwin Harari, Helen Herrman and James Barrett for their helpful comments on earlier drafts.

\section{REFERENCES}

Aponte, H. J. (1985) The negotiation of values in therapy. Fomily Process. 24. 323-338.

Australian Medical Association (1996) Code of Ethics. Australian Capital Territory: AMA.

Beauchamp, T. L. \& Childress, J. F. (1983) Principles of Biomedical Ethics. 2nd edn. New York: Oxford University Press.

Bloch, S., Hafner, J., Harari, E., et al (1993) The Fomily in Clinical Psychiatry. Oxford: Oxford University Press.

_. Szmukler, G., Herrman, H., et al (1995) Counseling caregivers of relatives with schizophrenia: Themes. interventions, and caveats. Fomily Process, 34, 413-425.
Department of Health (1996) The Protection and Use of Patient informotion. London: HMSO.

Doherty, W. \& Boss, P. (1991) Values and ethics in family therapy. In Hondbook of Fomily Theropy. vol. 2 (eds A. S. Gurman \& D. P. Kniskern). Pp. 606-637. New York: Brunner/ Mazel.

Falloon, I. R. \& Pedorson, J. (1985) Family management in the prevention of morbidity of schizophrenia: the adjustment of the family unit. British journal of Psychiotry, 147, 156-163.

Fievdsteel, N. D. (1982) Ethical issues in family therapy. In Ethics and Values in Psychotheropy: A Guidebook (ed. M. Rosenbaum). New York: Free Press.

General Modical Council (1995) Confidentiolity: Duties of o Doctor. London: GMC.

Goldenbers, I. \& Goldenberg, H. (1991) Family Therapy: An Overview, 3rd edn. Pacific Grove, CA: Brookes/Coles.

Lakin, M. (1983) Ethical lssues in the Psychotheropies. New York: Oxford University Press.

Lam, D. H. (1991) Psychological family intervention in schizophrenia: A review of empirical studies. Psychological Medicine, 21. 788-801.

Marzolin, G. (1982) Ethical and legal considerations in marital and family therapy. American Psychologist. 37. 788-801. 